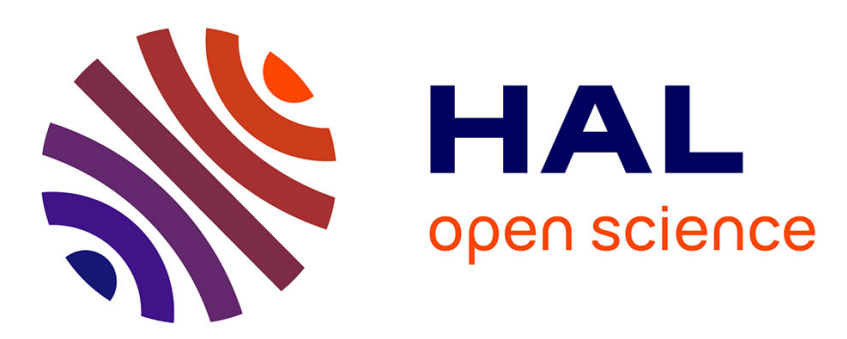

\title{
The DESERVE project: Towards future ADAS functions
}

Matti Kutila, Pasi Pyykönen, Paul Van, Nereo Pallaro, Joshué Pérez Rastelli

\section{To cite this version:}

Matti Kutila, Pasi Pyykönen, Paul Van, Nereo Pallaro, Joshué Pérez Rastelli. The DESERVE project: Towards future ADAS functions. IEEE SAMOS conference, Jul 2014, SAMOS, Greece. pp.308 - 313, 10.1109/SAMOS.2014.6893226 . hal-01086885

\section{HAL Id: hal-01086885 \\ https://hal.inria.fr/hal-01086885}

Submitted on 25 Nov 2014

HAL is a multi-disciplinary open access archive for the deposit and dissemination of scientific research documents, whether they are published or not. The documents may come from teaching and research institutions in France or abroad, or from public or private research centers.
L'archive ouverte pluridisciplinaire HAL, est destinée au dépôt et à la diffusion de documents scientifiques de niveau recherche, publiés ou non, émanant des établissements d'enseignement et de recherche français ou étrangers, des laboratoires publics ou privés. 


\section{The DESERVE project: Towards future ADAS functions}

\author{
Matti Kutila, Pasi Pyykönen \\ VTT Technical Research Centre of Finland \\ Tampere, Finland \\ matti.kutila@vtt.fi,pasi.pyykonen@vtt.fi
}

\author{
Nereo Pallaro \\ Centro Ricerche FIAT \\ Turin, Italy \\ nereo.pallaro@crf.it
}

\author{
Paul van Koningsbruggen \\ Technolution B.V. \\ Gouda, the Netherlands \\ paul.van.koningsbruggen@technolution.eu
Joshué Pérez-Rastelli
INRIA \\ Le Chesnay Cedex, France \\ joshue.perez_rastelli@inria.fr
}

\begin{abstract}
This article introduces the objectives and structure of the European research project DESERVE that is co-funded by the ARTEMIS-JU and national funding bodies. The project started in September 2012 with a duration of 3 years. The project aims to establish a new embedded SW and HW design by using a more efficient development process (including the enabling general platform concept and tool chain) in order to overcome challenges in reducing component costs and development time of future ADAS functions for modern vehicles. Both the process and the platform concept will be demonstrated with innovative ADAS functions in 3 passenger cars, 1 truck and 1 motorcycle.
\end{abstract}

Embedded hardware and software units have been developed for improving electronic horizon band of vehicles by detecting objects in front. Moreover, driver/motorcycle rider awareness is analysed by monitoring his/her actions online. The systems need to be robust and reliable in different environment conditions (night time, rain, etc.). The DESERVE platform distinguishes three layers of intelligence: perception, application and intervention\&warning control. The demonstrators will be based on software development tools from Elektrobit (ADTF) and Intempora (RTmaps). These tools are used to create 10 innovative ADAS applications as part of an integral ADAS development platform, following a new design and development process. Since the project is highly application oriented, the requirements have been adapted mainly from the ISO 26262 standard and the AUTOSAR framework which ensures compatibility with the existing automotive software environment.

Keywords-component: automotive, ADAS, function, driver monitoring, camera, traffic safety, embedded systems

\section{INTRODUCTION}

DESERVE is a research project which started in September 2012 and is due to finish in August 2015 (see Fig. 1). It is cofunded by the European Commission under the Artemis Joint Undertaking programme. The project is a joint effort of major vehicle manufacturers (Volvo, Daimler), automotive research centres (CRF), component suppliers (Continental, Ficosa,
AVL, Bosch, NXP, Infineon, dSPACE, ASL Vision, Ramboll, TTS, Technolution), research institutes (VTT, ICOOR, ReLab, INRIA, CTAG) and universities (VisLab, IRSEEM, ARMENIS, IKA, INTEMPORA, University of Hannover) to establish a "new" design and more efficient development process (including the enabling general platform concept and tool chain) in order to achieve a reduction in costs of components and development time of future ADAS functions for modern vehicles.

\begin{tabular}{|c|c|c|c|c|}
\hline & SUB-PROJECT & Year 1 & \multirow[t]{2}{*}{ Year 2} & Year 3 \\
\hline 1 & Requirements & Ext & & \\
\hline 2 & ADAS Development platform & & & \\
\hline 3 & Driver Behaviour - HMI & & & \\
\hline 4 & Test Case Functions & & & \\
\hline 5 & Integration and Tests & & & \\
\hline 6 & Validation and Evaluation & & & \\
\hline 7 & Dissemination and Exploitation & & & \\
\hline 8 & Project Management & & & \\
\hline
\end{tabular}

Fig. 1. DESERVE gantt chart

The DESERVE process and platform should enable vehicle manufacturers and their suppliers to manage the expected increase of function complexity together with the required reduction of costs (fixed and variable). The DESERVE platform itself is based on the following principles: standardisation of the interfaces, software (SW) reuse, development of common non-competitive SW modules, and easy and safety-compliant integration of standardised hardware (HW) or SW from different suppliers (for specific project objectives, see Table 1).

The DESERVE design process uses the innovative design space exploration (DSE) methodology. It is envisaged that by using the DSE concept both system design costs and time can be reduced by more than $15 \%$. The DESERVE project will build an innovation ecosystem for European leadership in 
ADAS embedded systems, based on the automotive R\&D actors, with possible applications in other industrial domains.

In addition to the embedded DESERVE design process, the platform adopts an advanced human-centred design strategy. At the end all ADAS functions will support the vehicle driver and motorcycle rider. The developed applications will provide natural and friendly support to the driver and rider, with proper levels of overall functional safety also during complex or emergency manoeuvres. The former human factors experiences in AIDE (in European Framework Programme 6) and interactIV (in European Framework Programme 7) projects will be utilised to develop user friendly HMI solutions which adapt according to the driver [1].

TABLE I. THE OBJECTIVES OF THE DESERVE PROJECT

\begin{tabular}{|c|c|}
\hline Scientific and Technical objectives & Measurable and verifiable form \\
\hline $\begin{array}{l}\text { The definition and implementation of } \\
\text { a model-driven process for the } \\
\text { compositional development of safety } \\
\text { critical systems that allows the } \\
\text { smooth integration of existing } \\
\text { components and functions in a new } \\
\text { framework }\end{array}$ & $\begin{array}{l}\text { By defining an analysis methodology } \\
\text { to establish an industrially applicable } \\
\text { process for exploration of design } \\
\text { spaces and multi-criteria constraint } \\
\text { satisfaction, with particular regard to } \\
\text { safety properties. } \\
\text { Verification: } 90 \% \text { or more of the } \\
\text { applications identified could be } \\
\text { developed with the proposed } \\
\text { platform }\end{array}$ \\
\hline $\begin{array}{l}\text { The development of an innovative } \\
\text { embedded vehicle platform capable } \\
\text { of supporting the fast and reliable } \\
\text { development of ADAS and efficient } \\
\text { Eco-driving functions }\end{array}$ & $\begin{array}{l}\text { By implementing demonstrators for } \\
\text { active and passive safety of drivers } \\
\text { and all road users in the three macro- } \\
\text { areas in the automotive domain such } \\
\text { as: } \\
\text { - Technical, safety and efficiency } \\
\text { impact assessment of resulting } \\
\text { prototypes following the } \\
\text { evaluation methodologies } \\
\text { identified in project PREVAL } \\
\text { and in line with } \\
\text { INTERACTIVE evaluation } \\
\text { methodologies } \\
\text { Cost-Benefits analysis } \\
\text { - Evaluation of cost reduction in } \\
\text { comparison with conventional } \\
\text { Driver Assistance Systems. } \\
\text { Verification: } 90 \% \text { or more of the } \\
\text { developed applications showed } \\
\text { more than } \mathbf{1 5 \%} \text { of reduction in } \\
\text { development time and cost. }\end{array}$ \\
\hline $\begin{array}{l}\text { The integration of existing vehicle } \\
\text { sensors and actuators in a unified } \\
\text { SW framework for multiple safety } \\
\text { and Eco-driving applications }\end{array}$ & $\begin{array}{l}\text { Existence of a cost-effective and } \\
\text { flexible SW platform, able to be used } \\
\text { with available sensors/actuators. } \\
\text { Verification: } 90 \% \text { or more of the } \\
\text { developed applications show more } \\
\text { than } 15 \% \text { reduction in development } \\
\text { duration and cost. }\end{array}$ \\
\hline $\begin{array}{l}\text { The adaptation of the current data } \\
\text { fusion, HMI and driver's behaviour } \\
\text { modules to provide suitable and } \\
\text { harmonised middleware for the } \\
\text { different safety and Eco-driving } \\
\text { functions }\end{array}$ & $\begin{array}{l}\text { By applying the V-model and } \\
\text { developing high level services and } \\
\text { Application Protocol Interface (API) } \\
\text { that can be used in a wide range of } \\
\text { safety-related use cases. } \\
\text { Via multi-modal HMI with user } \\
\text { related and driver behaviour } \\
\text { assessment through tests in driving } \\
\text { simulator and in prototype vehicles } \\
\text { Verification: Statistical evidence of } \\
\text { improvement of driver acceptance }\end{array}$ \\
\hline
\end{tabular}

\begin{tabular}{|l|l|}
\hline & $\begin{array}{l}\text { between existing (on the market) } \\
\text { and DESERVE-developed } \\
\text { functions. Subjective evaluation } \\
\text { through questionnaires. }\end{array}$ \\
& \\
\hline $\begin{array}{l}\text { The implementation of a new method } \\
\text { and relative tools for ADAS } \\
\text { functions development }\end{array}$ & $\begin{array}{l}\text { Existence of new tools for } \\
\text { development of Driver Assistance } \\
\text { Systems, including data fusion } \\
\text { visualisation, algorithm development, } \\
\text { actuation simulation, etc. } \\
\text { Verification: Evidence that the } \\
\text { method is suitable for effective } \\
\text { ADAS developments: } \\
\text { Results of the test case } \\
\text { development } \\
\text { Results of workshops with } \\
\text { main stakeholders, OEMs and } \\
\text { automotive suppliers. }\end{array}$ \\
\hline
\end{tabular}

The project has identified the following clusters of vehicle driver and motorcycle rider assistance support applications for which the integration of functions in a DESERVE-like platform is a cost-efficient option:

- Lane change assistance system

- Pedestrian safety systems

- Forward/rearward looking system (distant range)

- Adaptive light control

- Park assistant

- Night vision system

- Cruise control system

- Traffic sign and traffic light recognition

- Map supported systems (Note: only DAS scope, no driver information)

- Vehicle interior observation

The DESERVE development platform distinguishes three layers of intelligence: perception, application and intervention\&warning control. The perception layer includes various environment perception modules. This layer is compatible with the architecture coming from the interactIVe (EU-FP7) project. In addition, a plan concerning the prototypes has been created in order to connect radars, cameras and digital maps to the different DESERVE demonstrators.

In the end, the complete system architecture will be technically evaluated. Therefore the DESERVE project includes a series of demonstrators in which five different demonstration vehicles will be used to verify whether the process and the platform are easily implementable in different vehicle brands and models :

- 3 Passenger cars (Mercedes and CRF)

- 1 Heavy commercial vehicle (Volvo)

- 1 Motorcycle (Ramboll) 


\section{STRUCTURE OF THE PROJECT}

The project steering group represents a good mixture of academic and industrial partners [2]. The project coordinator and chair of the steering group is VTT Technical Research Centre of Finland. The coordinator is in charge of all administrative work and communication with the project's international funding organisation (Artemis-JU). In addition, a Technical Manager (Technolution B.V., the Netherlands) was selected to supervise the technical quality and progress of the work packages. The Technical Manager also belongs to the project steering group, as Fig. 2 shows.

The project has been divided into 8 sub-projects and the leading partner was nominated to follow the technical progress and resource allocation of the work packages. All sub-project leaders are also members of the steering group.

- SP1 Requirements and Specifications: Daimler

- SP2 ADAS development Platform: INRIA

- $\quad$ SP3 Driver behaviour - HMI: ICOOR

- SP4 Test Case Functions: Bosch

- $\quad$ SP5 Integration and Tests: CRF

- SP6 Validation and Evaluation: CRF

- $\quad$ SP7 Dissemination and exploitation: ICOOR

- $\quad$ SP8 Project Management: CRF

In addition the project includes two supportive functions:

- Quality manager: ICOOR

- IPR manager: CRF

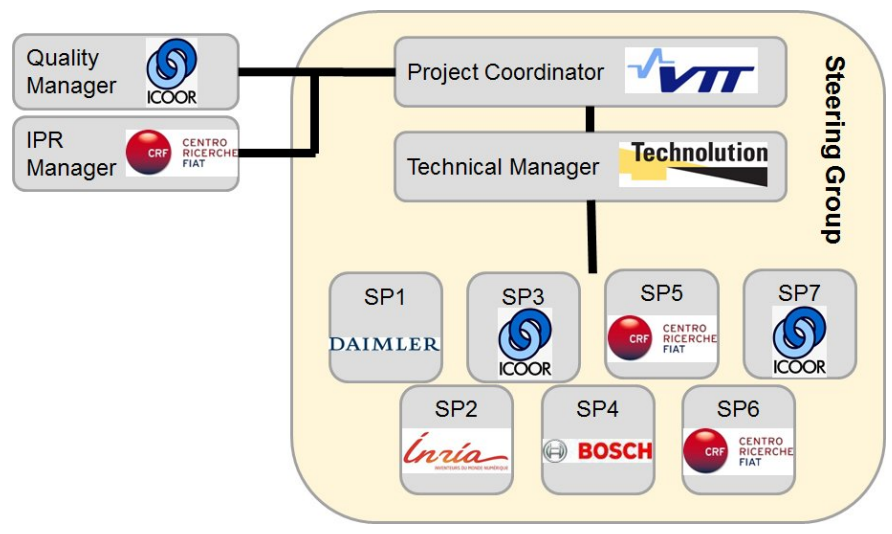

Fig. 2. DESERVE project steering group composition

\section{PROJECT VISION}

DESERVE's design and development process is based on the well-known V-model. This model is tuned to the design and development of ADAS functions which are the functional building blocks and has been integrated into the DESERVE platform (see Fig 3). Two elements are essential in this process. The first one is the distinction of the three layers of the system intelligence: perception, application and intervention\&warning control. In the design phase, each ADAS function will be decomposed in these three layers. In the implementation phase, the existing functional building blocks will be re-used and missing functional building blocks will be developed for each layer. The newly developed building blocks can be re-used by other ADAS functions, too.

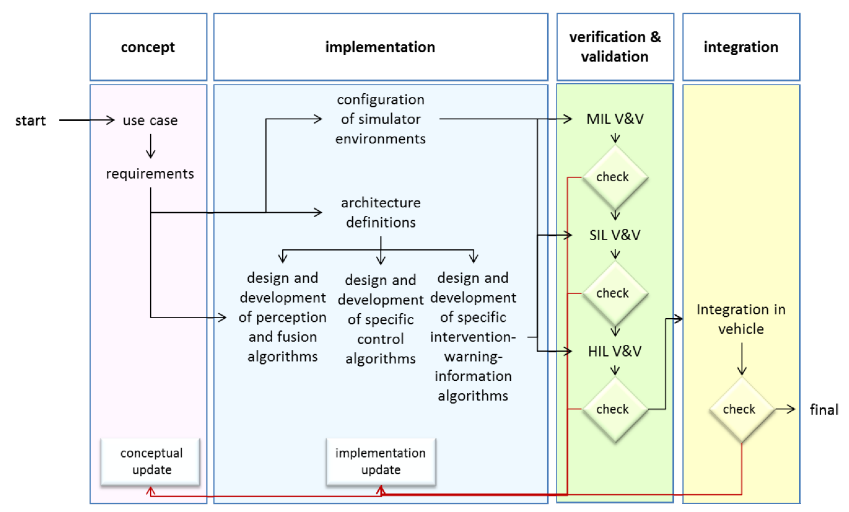

Fig. 3. Stepwise design, development and validation

The second element is the stepwise verification and validation of the ADAS functions. The strictly functional design of an ADAS function will be verified and validated in the Model-in-the-Loop (MiL) environment. The validation function will be implemented by using the developed software. Functionality and stability of these software components will be verified and validated in a Software-in-the-loop (SiL) environment. The validated software components will be integrated and embedded in a Hardware-in-the-Loop (HiL) environment. Here the new ADAS functions running on an embedded controller can be verified and validated with respect to the non-functional requirements, (e.g. performance, robustness and security).

Once a new function has successfully passed all verification and validation phases, the perfect design is available for ADAS functions dedicated hardware design, development and production. This dedicated hardware should fit in (or is already available in) a common in-vehicle platform for current and future ADAS functions. This platform should be compliant with AUTOSAR.

\section{DEVELOPMENT PHASES AND CONSTRAINS}

Development phases are based on the research hypotheses and validation plan perspectives of the DESERVE project [3]. These phases are defined as follow:

- Requirement definitions: these were developed based on the application and platforms needs and the different demonstrators (section VI) [4];

- Collecting information: the requirements will be used to define the performance indicators of the project related to the ADAS development platform and driver behaviour analysis;

- Development times: each partner will provide its prior data of the developed ADAS functions which will be compared later on with the data of the redesigned and redeveloped ADAS functions following the DESERVE approach ;

- Test case functions: these will be used to validate the data when measuring the performance of the system 
according to the selected key performance indicators (Section V);

- Integration and test: This phase integrates all the functions developed on the selected physical platform. Furthermore testing of the whole integrated ADAS system will take place in this phase;

- Validation and Evaluation: This phase analyses the collected data for evaluating if the overall research hypothesis has been reached.

The constraints have been identified with reference to the data collection for calculating the key performance indicators. Some of the indicators could not be measured in the beginning since the development of the platform was pending and no prior data was available. For this reason, the project will focus on reaching the general platform requirements [4] instead of the detailed ones. The generic requirements (mainly from the standards ISO 26262 [5] and AUTOSAR [6]) apply only to the "industrialized" platform versions and not for the individual modules that are developed in DESERVE rapid prototyping platform framework.

DESERVE functionalities push forward the situation compared to the current approaches in the automotive industry. The used architecture for the DESERVE platform is flexible and modular and enables to add new software components, devices, modules and functions even if the set of vehicle sensors, actuators and HMI remains.

\section{PERFORMANCE INDICATORS}

Performance Indicators (PIs) are defined as quantitative or qualitative measurements. They are assigned as an index or other values for monitoring process intervals and can be compared with diverse criteria. PIs can be divided in objective indicators (which can be measured) and subjective indicators (questionnaire items, interview results, etc.) as in [7]. In this section, a description of the selected performance indicators is presented [8]:

\section{A. Objective indicators}

- Architecture describes how the process and the performance of the global embedded architecture are improved;

- Sensors validates the performance of the different perception devices to be connected in the DESERVE platforms;

- Actuators (pedal and steering wheel) performance is measured in term of response and attrition;

- HMI will measure the performance of the user interfaces. The improvements of the DESERVE solution will be compared to the prior prototypes including virtual driving environments;

- Development times indicate the time required to develop the hardware and software functions;

- Software measures the ability to add and remove different perception systems and functions to the ADAS systems. It is crucial to assess the performance of the software and verify that its functionality is as expected. One major challenge is to test real time behaviour of the different applications.

\section{B. Subjective indicators}

- Hypothesis: The proposed research hypotheses have to be answered by the achievements of the DESERVE project [6]. The summarised DESERVE hypothesis is: the project will provide a low cost, highly reliable, standardised Tool Platform, that can seamlessly integrate different functions, sensors, actuators and HMI to enable the development of a new generation of ADAS applications;

- Client objectives: The systems have to be user friendly for the drivers and customers. Clients consider that most of the ADAS are important for safety [9];

- Human factor: Interaction with drivers is important for the HMI and shared driving control. This indicator is for testing the acceptance rate and usability of the HMI, safety measurements such as Time to Collision, Time Headway, mean speed, etc.;

- Confidence: the system and their different features have to convey confidence to the drivers and passengers.

\section{DEMONSTRATIONS}

DESERVE aims to develop a reliable software design by using simulation (MIL, SIL , HIL), which will avoid additional iterations in the vehicle testing. Simulations will be utilised for code optimisation and so on, resulting in lower time and costs for the testing and validation phases and providing a comprehensive set of test scenarios.

To demonstrate the former key benefit of the DESERVE platform, the project addresses two demonstration phases:

- Laboratory and road testing to ensure the complete functionality of the DESERVE development platform and of the integrated functions before validation;

- Integration of the DESERVE platform system and safety functions into vehicle demonstrators, and validation.

The following safety and driving support applications will be integrated in the vehicle and motorcycle demonstrators:

- $\quad$ AEB pedestrian, driver distraction and driver intention - CRF, passenger car;

- Inter Urban Assist - Daimler, passenger car;

- AEB interurban, driver distraction \& drowsiness and driver intention - CRF, passenger car;

- Adaptive Cruise Control (ACC) and Collision Warning \& Emergency braking (CWEB) - Volvo, truck.

- $\quad$ Rider monitoring - Ramboll, motorcycle.

Each application to be designed, simulated (MiL, SiL, HiL) and integrated on the demonstrator can been represented by a functional block diagram, as shown in Figure 4. It shows the main software building blocks of the three platform layers (perception, application and intervention\&warninginformation), that will be developed with different tools:

- $\quad$ Perception modules (RTMaps/ADTF)

- Application and IWI modules (Matlab/Symulink) 


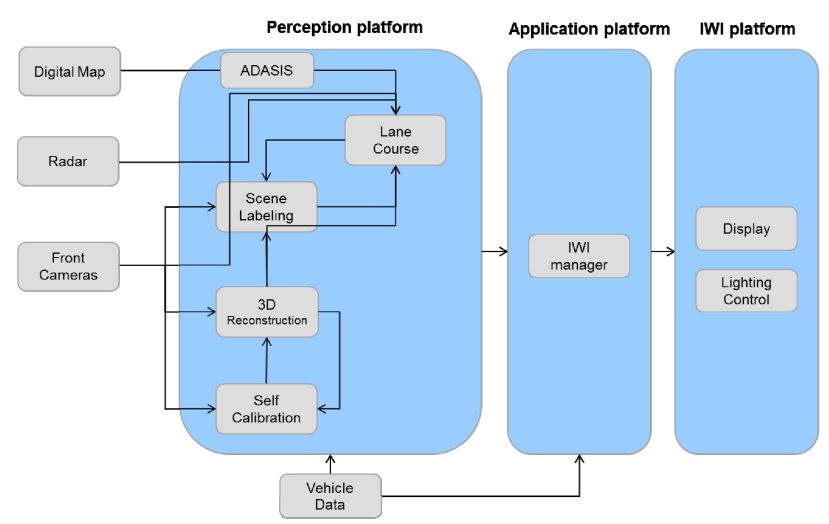

Fig. 4. The draft functional block diagram of Inter Urban Assist

The driver and rider status monitoring is a transversal driving support function within DESERVE, enabling the optimisation of the warning and actuation strategies in the roadmap of the integrated safety systems. In Figure 5, the driver monitoring system based on different detection principles is shown.

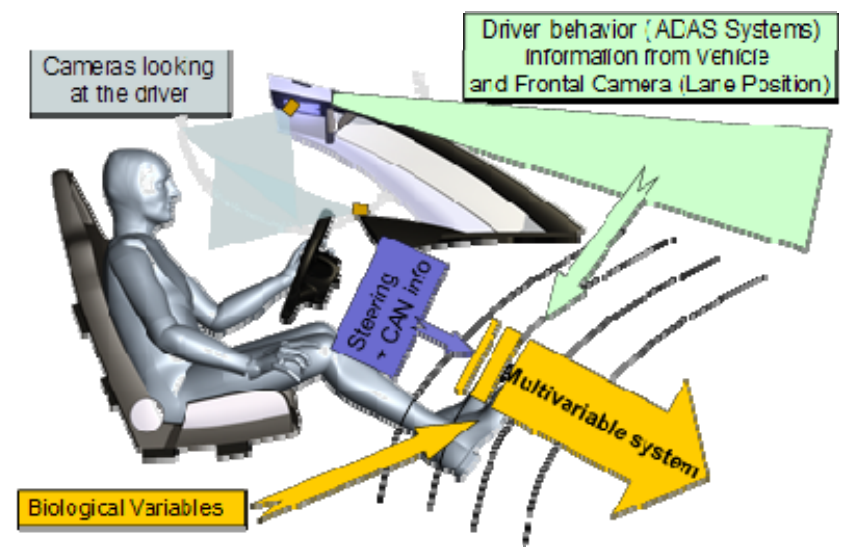

Fig. 5. Driver status monitoring

\section{THE OUTCOMES OF THE PROJECT}

The project main results addressing the future ADAS functions for novel vehicles will be demonstrated in three passenger cars, one truck and one motorcycle. The partners have agreed to implement the embedded hardware and software units onto these demonstrators. The In-vehicle hardware and software concept consists of sensors and whether on the dSPACE MicroAutoBox with ADTF or RTMaps platform. Automotive Data and Time-Triggered Framework (ADTF) and RTMaps represent software platforms to connect the vehicle sensor systems together. In the motorcycle environment, the software concept is based on the RTMaps framework with Intel-based embedded automotive PCs.

The DESERVE software architecture includes the three layers: perception, application and intervention\&warning information. The perception layer contains different sensors and applications like software drivers. The Application platform is the data processing unit which utilizes sensor information i.e. camera data. The five ADAS functions:

- Automatic Emergency Braking

- Inter Urban Assist

- Interurban Automatic Emergency Braking

- Adaptive Cruise Control and Collision Warning \& Emergency braking

- Motorcycle rider monitoring

will be demonstrated in 5 different types of demonstration vehicles including passenger cars, truck and motorcycle.

In the motorcycle demonstrator, the main focus in the application layer is to implement the first rider monitoring system by using embedded hardware modules. In this demonstration, the challenge is to improve visibility of rider's eyes trough a visor of a helmet. The driver monitoring system is also successfully extended to operate in driving simulators in which a multiple camera setup is needed. This will enable driver monitoring in all DESERVE-compliant vehicles (i.e. heavy good vehicles).

The DESERVE project has shown that it is possible to develop a common platform in which different sensors and software modules are fused even if the outputs are different. The developed sensor system can operate in different environments (night time, rain, etc.), for example detecting objects in front or sensing awareness of the driver.

\section{DISCUSSION AND CONCLUSIONS}

The project target is to develop a common software platform for modern vehicles. The expected outcome is that the platform fits up to $90 \%$ of all new applications. The novel ADAS functions are becoming ever more complex and the new features are software-based instead of mechanical solutions like they were 10 to 15 years ago. However, software is always prone to errors which may have serious consequences if e.g. the vehicle accelerates when emergency braking is expected. Therefore, a proper evaluation procedure is needed by using proper performance indicators, in order to verify the correct functionality of the platform.

Two alternative solutions have been proposed by the DESERVE partners. One bases on ADTF which is mainly utilised by the German automotive industry and RTMaps which is implemented by the other demonstrators. Since the aim is to introduce a solution which will be exploited in real vehicles both solutions are allowed. This makes it more likely to be implemented not just during the project but also during the production after the development phase.

Four demonstrator case studies have been introduced by the project. The aim is to bring all the technology developed in the project to be viable in real driving situations. The DESERVE project is one of the main efforts in Europe in which the automotive industry, the supplier chain and academic partners are working together to improve the level of ADAS functionality. 


\section{ACKNOWLEDGMENT}

The DESERVE project with grant agreement no. 295364.has been co-funded by the European Commission under the Artemis Joint undertaking and national funding bodies.

\section{REFERENCES}

[1] Amditis, A., Pagle, K., Tsogas, M., Bekiaris, E., Panou, M., Tattegrain, H., Bellet, T., Boverie, S., Kutila, M. \& Markkula, G. 2007. A Real Time Platform for Estimating the Driver - Vehicle - Environment State in AIDE Integrated Project. Proceedings of the 14th World Congress on ITS. 9-13 Oct 2007. China, Beijing.

[2] Kutila, M., Jokela, M., Fruttaldo, S., Montanari, R. \& Pallaro, N. 2014. Project ownership and steering committee challenges in international context. the 2014 International Conference on Economics, Management and Development (EMD2014). Interlaken, Switzerland. 22-24 Feb 2014.
[3] Ritter, W. et al. 2014. Application Database. The DESERVE project deliverable D11.1.

[4] Pallaro, N. 2013. Development Platform Requirements. The DESERVE project deliverable 12.1 .

[5] General Structure of ISO 26262. ISO standard.

[6] AUTOSAR. Web site available in www.autosar.org. cited on $22 \mathrm{Feb}$ 2014.

[7] Bakri, T., Blanco, R., Fahrenkrog, F., Koskinen, S., Larsson, A., Larsson, P., Malone, K., Saéz, M., Sánchez, D., Várhelyi, A., Willemsen, D., Zlocki, A. 2011. Requirements for the Evaluation Framework.. The deliverable 7.1 of the interactIVe project.

[8] Perez, J. et al. 2013. Research Hypothesis and performance indicators. The DESERVE project deliverable 61.1.

[9] European Consumers' Desirability and Willingness to Pay for Advanced Safety and Driver Assistance Systems. Frost \& Sullivan. 2010. 